\title{
La Nulidad de Cosa Juzgada Fraudulenta y la Acción de Amparo Constitucional
}

Aníbal Quiroga León*

\section{Introducción}

Desde que se dio vigencia al Texto Único Ordenado (TUO) del Código Procesal Civil, algunas de sus regulaciones aparecen ciertamente discutidas y discutibles por falta de una clara concepción dogmática, ausencia de razonabilidad (como el caso del abandono del proceso) o, incluso, claridad o sintaxis, cuando no por haberse configurado de modo reñido al uso adecuado del idioma castellano.

Una de estas instituciones, que se ha hecho aparecer como "novísima», es la referida a la «nulidad de cosa juzgada fraudulenta», cuyos alcances y limitaciones han sido desbordados por la práctica sobre la base de una inadecuada e insuficiente redacción del texto normativo, sobre todo si se la enfrenta a la naturaleza jurídica diferente de otro tipo de pretensiones materiales no convalidables por medio de un proceso civil, familiar, contractual, personal, etc., como, por ejemplo, a los alcances de las acciones constitucionales de amparo. En efecto, las normas en conflicto (que representan el enfrentamiento conceptual al que hoy en día se hallan expuestos los tribunales de justicia del país) dicen a la letra:

TUO del Código Procesal Civil

"Art. 178. - Nulidad de cosa juzgada fraudulenta. - Hasta dentro de seis mesis de ejecutada o de haber adquirido la calidad de cosa juzgada si no fuere ejecutable, puede demandarse, a través de proceso de conocimiento, la nulidad de una scrinnnrir $n$ del acuendo de las

\footnotetext{
* Profesor Asociado de la Facultad de Derecho de la Pontificia Universidad Católica del Perú y de la Maestría en Derecho Empresarial de la Escuela de Post-Grado de la Universidad de Lima. Vocal Suplente de la Corte Superior de Jus.icia de Lima.
} 
partes homologado por el Juez que pone fin al proceso, alegando que el proceso en que se origina ba sido seguido con dolo, fraude, colusión o afectando el derecho a un debido proceso, cometido por una, o por ambas partes, o por el Juez, o por éste y aquéllas.

Puede demandar la nulidad la parte o el tercero ajeno al proceso que se consideren directamente agraviados por la sentencia, de acuerdo a los principios exigidos en este Titulo.

En este proceso sólo se pueden conceder medidas cautelares inscribibles.

Si la decisión fuese anulada, se repondrán las cosas al estado que corresponda. Sin embargo, la nulidad no afectará a los terceros de buena fe y a titulo oneroso.".

Al lado de ello, tenemos como antecedente inmediato el artículo 1083 del Código de Procedimientos Civiles de 1912 (D), que a la letra decía:

\section{Código de Procedimientos Civiles de 1912 (D)}

"Art. 1083. - La sentencia recaida en el juicio ejecutivo; en los interdictos; en el juicio de divorcio; en el de desabucio, con la reserva establecida en el Art. 973; en el de alimentos; pérdida de la patria potestad; remoción, excusa y renuncia de los guardadores; asi como en las resoluciones que ponen fin al procedimiento para la declaración de herederos; apertura de testamentos cerrados y comprabación de testamentos privados o verbales; guarda y posesión de los bienes del ausente; adopción; inscripción y rectificación de partidas en los registros de estado civil e interdicción de incapaces, pueden ser contradichas en juicio ordinario. ${ }^{2}$.

"Art. 1084.- El juicio contradictorio de que se ocupa el artículo anterior, debe instaurarse dentro de dos meses contados desde la notificación de la resolución que pone término al juicio o procedimiento

\footnotetext{
En la versión original del Código Procesal Civil (Decreto Legislativo 768), este numeral tenía una redacción final, en un quinto parágrafo, que a la letra decia: «Si la demanda no fuera amparada, el demandante pagará las costas y costos doblados, $y$ una multa no menor de $30 \mathrm{ni}$ mayor de 100 remuneraciones mínimas vitales" (sic). Ello fue expresamente suprimido por omisión por el decreto ley 25940, modificarorio del Código Procesal Civil (cien artículos, aproximadamente), antes de su entrada en vigor (11.12.92).

Versión original del Código. Después de 1936 en todos los textos legales se ha subrayado la mención al divorcio, pues la jurisprudencia de la Corte Suprema, uniformemente, luego del establecimiento del divorcio vincular en el Perú, excluyó de los alcances del artículo 1083 el supuesto normativo referido al divorcio por sus efectos terminales, en una interpretación abrogativa.
} 
que se contradice o desde la notificación de la resolución que, dando por devueltos los autos, manda cumplir lo ejecutoriado, salvo lo dispuesto en el Art. 24 del Juicio Ejecutivo.»3.

Y para los efectos comparativos, terminaremos con la transcripción del artículo 8 de la ley 23506, de amparo, hábeas corpus, hábeas data y acción de cumplimiento -según la remisión que a ella hace la ley 26301-, y que a la letra dice:

Ley 23506, de Amparo, Hábeas Corpus, Hábeas Data y Acción de Cumplimiento]

"Art. 8.- La resolución final constituye cosa juzgada únicamente si es favorable al recurrente. Puede oponerse a quien pretendiera ejecutar o ejecutarse igual agresión. ${ }^{4}$.

La cuestión principal que, a propósito de esto, desarrollaremos, se halla referida a la posibilidad jurídica de que se interponga válidamente acción de nulidad de cosa juzgada fraudulenta, basada en el artículo 178 del Código Procesal Civil, contra lo resuelto en una Acción de Amparo Constitucional previa, en los términos siguientes:

\section{Antecedentes}

La Sala Civil de la Corte Superior de Justicia expidió en discordia sentencia de vista en que, confirmando en todos sus extremos la sentencia de primera instancia materia de la apelación, declaraba fundada la acción de amparo constitucional interpuesta por un justiciable contra el Estado como consecuencia de la aplicación de los efectos de una determinada norma legal de orden tributario.

De conformidad con las actuales disposiciones legales sobre la materia (Ley de Amparo y Hábeas Corpus, modificatorias, complementarias y Ley orgánica del Tribunal Constitucional -LOTC-), lo anterior cons-

Texto modificado por el decreto legislativo 127 de 15 de junio de 1981.

Esto tenía base en los artículos 295,3 .r $^{\text {er }}$ parágrafo, y 298 , inciso 2 , de la Constitución de 1979, que establecían el principio de la "jurisdicción negativa de la libertad", en donde la resolución judicial favorable al demandante de la acción constitucional siempre se ejecutaba y quedaba firme, y la que le era adversa tenía legitimación y ulterior recurso ante el Tribunal de Garantías Constitucionales, como máximo órgano de control de la Constitución, acceso vedado para el demandado -normalmente la autoridad pública-, que quedaba retenida ante el órgano jurisdiccional. 
tituye cosa juzgada y el proceso judicial por acción de garantía constitucional concluye allí para todos sus efectos. Por ello mismo, y en aplicación de lo dispuesto por el artículo 42 de la ley 23506, fue publicada esta sentencia judicial en el diario oficial El Peruano, siendo el requisito de tal norma legal el que la resolución a publicarse sea final, consentida y ejecutoriada (sic).

El amparo legal de lo antes señalado, es el siguiente:

- El inciso 2 de la cuarta Disposición Transitoria de la ley 26435 (LOTC), que a continuación glosamos, y que a la letra señala:

"La Corte Superior conoce los procesos de garantía en segunda y última instancia, en vía de apelación. Contra la resolución denegatoria que ésta expide procede recurso extraordinario previsto en el Art. 41 de la presente Ley."

- El inciso 2 del artículo 202 de la Constitución Política del Estado establece como competencia del Tribunal Constitucional, en vía de $j u$ risdicción negativa de la libertad, el conocimiento en última y definitiva instancia de las resoluciones denegatorias de, entre otras, la acción de amparo constitucional.

Resulta entonces incuestionable que la resolución judicial final en materia de acción de garantía constituye cosa juzgada absoluta si es favorable al demandante, por lo que de darse un supuesto distinto al señalado expresamente en el texto inequivoco de la ley, el Tribunal Constitucional resultaría incompetente, ya que la competencia del Tribunal Constitucional en la jurisdicción negativa de la libertad se halla establecida por la Constitución, y no puede ser ampliada por interpretación alguna.

En el año en curso se ha publicado en el diario oficial El Peruano una resolución ministerial autoritativa al señor procurador público a cargo de los asuntos judiciales del Sector de que se trata, para que, en representación y defensa de los intereses del Estado, interponga contra el justiciable "y otros" $"$, acción judicial de nulidad de cosa juzgada fraudulenta por violación del debido proceso, conforme lo autoriza el artículo 178 del Código Procesal Civil.

El señor procurador público ha entendido por esos "otrosn a todos los magistrados intervinientes en el proceso judicial antecedente, procediendo a emplazarlos con la misma demanda, cual si fuesen parte en la relación jurídico-material del proceso objeto de la acción de nulificación. 
En la parte considerativa de dicha resolución ministerial se establece que en la acción judicial antecedente «se han cometido irregularidades y vicios procesales generando resoluciones nulas para el Estado, habiéndose llegado al extremo de expedirse en Segunda Instancia dos sentencias contradictorias, por lo que es necesario contradecirlas (sic) vía acción judicial sobre nulidad de cosa juzgada fraudulenta y nulidad de cosa juzgada [...]».

\section{Análisis}

La primera de las cuestiones que hay que determinar, para proceder al análisis de lo planteado, es la determinación de la naturaleza jurídica de la denominada "acción de nulidad de cosa juzgada fraudulenta» de que trata el artículo 178 del Código Procesal Civil, institución aparentemente novedosa por su denominación, pero con innegables antecedentes en nuestra normatividad procesal anterior y en la doctrina del Derecho procesal civil. Esta aparente novedad -que empieza precisamente por su actual denominación- determina el error en algunas de sus conceptualizaciones y que se trasunta en igual error en el posterior manejo judicial.

En efecto, la acción de "nulidad de cosa juzgada fraudulenta" tienie antecedentes normativos en lo dispuesto por los artículos 1082, 1083 y 1084 del Código de Procedimientos Civiles (D) de 1912, y en la concepción de la Cosa Juzgada Formal y Cosa Juzgada material. En efecto, el artículo 1082 del Código de Procedimientos Civiles (D) de 1912 establecía el principio de la Cosa Juzgada Material absoluta, determinando las características de inmutabilidad, inimpugnabilidad y coercibilidad como atributos de la institución de la cosa juzgada ${ }^{6}$ como garantía constitucional de la administración de justicia y, por ende, elemento esencial del debido proceso legal. Como contrapeso a lo anterior, el artículo 1083 del mismo texto legal señalaba aquellos procesos no plenarios en los que, en juicio plenario de conocimiento, se podía volver a controvertir lo ya juzgado -sea cual fuere el foro del juzgamiento anterior, en su inicio o en su final (incluso si la sentencia final hubiese sido dictada por la propia Corte Suprema de Justicia de la República)-, a través de la denominada acción de contradicción de sentencia . El artículo 1084 del ya acota-

Quroga Leon, Aníbal, "Las Garantias Constitucionales de la Administracion de fusticia" en: La Constitución diez años después, Fund. Naumann y Const. \& Soc., Lima, 1989, p. 323.

En esta relación, que la jurisprudencia de la Corte Suprema siempre interpretó como taxativa, se abrogó después de 1936 la referencia al "divorcion, y se entendió incluida a la acción de "aviso de despedida". 
do texto legal precisaba, en su última versión vigente dispuesta por el decreto legislativo 127, de 15 de junio de 1981, que el plazo de caducidad para el ejercicio de tal acción era de dos meses contados a partir de la notificación de la resolución que ponía fin al procedimiento que era materia de la contradicción o del cumplimiento de lo ejecutoriado. En consecuencia, los principios se enunciaban del siguiente modo: los procesos judiciales ordinarios tenían calidad de cosa juzgada material; los procesos sumarios y especiales relacionados en el artículo 1083 del Código de Procedimientos Civiles (D) tenían calidad de cosa juzgada formal temporal, adquiriendo la calidad de cosa juzgada material vencido el plazo del artículo 1084 del mismo texto legal, o si interpuesta la acción de contradicción de sentencia la Corte expedía sentencia definitiva, no susceptible a su vez de ulterior contradicción sobre tal materia.

Sobre este particular, parece ilustrativo reseñar lo que al respecto señala la Exposición de Motivos del Código de Procedimientos Civiles:

"Después de establecerse [art. 1080] que la sentencia recaida en juicio ordinario queda ejecutoriada en los tres casos alli puntualizados, se consigna la regla recíproca, enumerándose los juicios y los procedimientos no contenciosos cuyas resoluciones finales pueden ser contradichas en juicio ordinario. Ha sido necesario entrar en esa enumeración para que asi queden excluidos juicios y procedimientos no contenciosos en los cuales no cabe o no es conveniente conceder el derecho de contradecir la sentencia en la via ordinaria. [...] Algunos de dichos juicios [los excluidos] son ordinarios desde su iniciación. En otros casos, la oposición que se formule se sustancia, precisamente, en vía ordinaria; $y$, que es fácil descubrir examinando, ya la indole especial del juicio, ya las consecuencias y efectos irrevocables que tienen que producir las resoluciones expedidas»". (Lo agregado es nuestro.)

En consecuencia, aparece de la doctrina y de los antecedentes normativos que el rigor de la autoridad de la cosa juzgada (res iudicata) con que se inviste toda decisión judicial, que la hace finalmente inimpugnable, inmutable y coercible, $y$ que es base de la legitimidad y finalidad del proceso judicial (declaración de certeza), se aminore y humanice en determinados casos y bajo determinadas circunstancias, haciendo que el concepto de cosa juzgada adquiera una doble dimensión: la materialo

\footnotetext{
Comite de Reforma Procesal, Exposición de Motivos del Código de Procedimientos Civiles, San Marti y Co. Eds., Lima, 1912, rp. 315-316.
} 
sustancial, que es absoluta, y la formal ${ }^{9}$, que permite el volver a cuestionar (rejuzgar) lo que ha sido materia de la controversia judicial, en un proceso mayor, plenario, con mejores posibilidades probatorias, a fin de recuperar las situaciones de injusticia que pueden haberse generado y estarse beneficiando de la formalidad y rigor de la cosa juzgada.

Entre los antecedentes doctrinarios de la institución, que nos parecen más importantes reseñar, en la doctrina comparada, se pueden resumir los principales del modo siguiente: LIEBMAN ${ }^{10}$ señala que:

"Pero la sentencia puede ser contraria a la ley en cuanto al contenido, y esto produce su injusticia.

La nulidad invalida la sentencia como acto final del proceso $\%$ por consiguiente -salvo el caso de que el vicio sea tan grave que produzca una nulidad radical y absoluta-, puede ser hecha valer sólo en el mismo proceso con los medios de impugnación establecidos por la ley, y unicamente por las partes, que son los sujetos de la relación procesal y, por tanto, las únicas personas lesionadas por la nulidad e interesadas en hacerla reparar.

La injusticia se refiere, en cambio, a la sentencia juicio y puede depender tanto de un error de derecho cuanto de un error de hecho; en todo caso, la concreta voluntad del Estado es diversa de la declarada y puede, por consiguiente, perjudicar injustamente al tercero cuyo derecho sea de algún modo conexo con la relación decidida con la sentencia.»

Por su parte, Couture ${ }^{11}$ señala, al comentar el artículo 577 del Proyecto de Código de Procedimiento (uruguayo) de 1945, del que el artículo 178 aparece casi literalmente tomado, y que a la letra dice:

Proyecto de Código de Procedimiento de 1945 (Uruguay) "Art. 577.- Podrá pedirse, aun después de terminado el proceso, la anulación de los actos realizados mediante dolo, fraude o colusión.

Esta anulación podrá requerirse sólo por aquellos a quienes el dolo, fraude o colusión han causado perjuicio y de acuerdo a los principios mencionados en los articulos anteriores. Los terceros también pueden solicitar esta anulación.

LIEBMAN, Enrico Tullio, Eficacia y autoridad de la sentencia, EDIAR S.A. Eds., Buenos Aires, 1946, pp. 76-77.

Op. cit. pp. 170-171.

Couture, Eduardo J., Estudios de Derecho procesal civih t. III, Eds. Depalma, Buenos Aires, $1979,3 .^{2}$ ed., pp. 387-404. 
Si los actos fueren anulados, se repondrán las cosas en el estado anterior a los mismos. Pero en ningún caso la anulación podrá perjudicar a terceros de buena fe ni anular los actos y contratos celebrados con el dueño aparente de los bienes."

Aquí se establece la anulación de los actos (procesales) realizados mediante dolo, fraude o colusión, que según señala en fundamento:

"[...] La segunda situación es la que surge cuando el fraude lesiona el derecho de los terceros. Estos pueden, entonces, promover la impugnación del fraude por los medios ordinarios y por medios de una demanda autónoma de revocación o anulación de los actos fraudulentos.

[...]

10. Función de la demanda revocatoria

El instituto que motiva estas reflexiones puede concretarse en los tres conceptos que le sirven de denominación: a) es pretensión (en el sentido de demanda) revocatoria; b) funciona contra la cosa juzgada; c) cuando esa cosa juzgada ha sido obtenida mediante fraude o colusión.

[...]

11. La revocación

La demanda a promoverse [...] tiende a destruir o revocar la cosa juzgada. Esta noción surge del primer examen.

Pero conforme se profundiza, aparece un problema de verdadera significación. Se trata de saber si la nueva acción o demanda tiende a destruir totalmente la cosa juzgada, o si su función consistirá tan sólo en destruirla en cuanto apareje perjuicio al tercero.

[...]

15. Revocación y anulación

En tanto [...] hemos hablado de revocación, en el Proyecto hemos hablado de anulación.

[...]

La revocación supone un acto formalmente válido y sustancialmente injusto. La anulación supone un acto formalmente vicioso $y$ sustancialmente injusto. En el primero, el molde es bueno y la sustancia es mala; en el segundo, el molde y la sustancia son malos.

La noción de revocación se refiere, pues, al contenido y no al continente. La noción de anulación se refiere al continente y al contenido.

El Proyecto habla de anulación porque dentro de la sistemática del mismo la idea de nulidad se halla siempre condicionada por el contenido del acto. Si el acto es formalmente nulo pero sustancialmente 
justo, no procede en el Proyecto la anulación. Ésta sirve sólo para corregir actos nulos e injustos: los válidos e injustos se corrigen por otros medios; los nulos y justos no se corrigen, pues quedan legitimados por su propia justicia."

La antigüedad de la discusión acerca de la relativización de la fuerza y autoridad de la cosa juzgada en la búsqueda de la humanización del proceso judicial, como medio y no como fin en sí mismo (a partir de la conceptualización de la cosa juzgada formal), data del Derecho Romano, en donde se consideraron figuras procesales como la exceptio doli, replicatio doli y, sobre todo, la restitutio ad integrum (restitución por entero), esta última como posibilidad de volver a discutir judicialmente una decisión judicial de orden previo en casos excepcionales de injusticia, buscando volver las cosas al estado anterior al de la sentencia injusta, esto es, reparar las cosas al estado de una nueva sentencia justa, obviamente en un nuevo proceso judicial.

El Código Procesal Civil ha consagrado en el artículo 178, sin mayor precisión jurídica y con evidentes errores de redacción (como la práctica se ha encargado de demostrar), la disposición que consagra la "Acción de Nulidad de Cosa Juzgada Fraudulenta», que, como aparece evidente de este numeral, es el único que regula esta institución -por lo menos en el Código de Procedimientos Civiles de 1912 (D) mereció dos-, y donde sus características de la misma pueden ser reseñadas del siguiente modo:

i) Se trata de un nuevo proceso judicial, el nulificante;

ii) Pueden demandar como legitimados activos quien fue vencido en el proceso antecedente, los terceros allí apersonados o los terceros no apersonados a quienes afecte el derecho que allí se determinó en sentencia ejecutoriada;

iii) El plazo de caducidad es de seis meses de ejecutada la sentencia del proceso antecedente o de haber adquirido ésta calidad de cosa juzgada, con lo que se vuelve al plazo original del Código de Procedimientos Civiles de 1912 (D) antes de su modificación por el decreto legislativo 127 ;

iv) El trámite del proceso nulificante es el que el Código concede al proceso de conocimiento (el más lato); 
v) La naturaleza procesal del proceso antecedente no se halla definida. Luego, puede ser un proceso de conocimiento ${ }^{12}$, procesos de ejecución, y procesos no contenciosos. Se excluyen los procesos cautelares, en la medida en que siempre son subsidiarios a uno mayor, y en aplicación de lo dispuesto en la concordancia de los artículos 612, 617, 636 y 640 del Código Procesal Civil;

vi) Las medidas cautelares que se soliciten u obtengan se hallan expresamente limitadas o restringidas, pues sólo pueden ser de carácter inscribible o registral con el objeto de enervar la "buena fe registral»;

vii) La sentencia anulatoria debe reponer las cosas al estado anterior, rejuzgando en el proceso nulificante las pretensiones jurídicas del proceso antecedente, en todo o en parte, y determinando una nueva y diferente consecuencia jurídica, según sea el caso; y

viii) La sentencia nulificante es oponible erga omnes, con excepción de quienes hayan derivado sus derechos de la sentencia antecedente de buena fe y a título oneroso, descartando con ello a quienes hayan obrado de mala fe, sea a título oneroso o no, y a quienes aún obrando de buena fe hubieren derivado su derecho de la sentencia antecedente a título gratuito.

En consecuencia, aparece evidente que puede interponerse acción de nulidad de cosa juzgada fraudulenta sobre la sentencia ejecutoriada de cualesquier proceso judicial -con excepción de los procesos cautelares, por su propia racionalidad subsidiaria, mutable, transitiva y provisional-, cualquiera sea su naturaleza y tipo de pretensión o pretensiones, ya que la norma del Código Procesal Civil no limita el marco material de aplicación (tipo de proceso precedente o tipo de pretensión precedente), siempre que se acuse a la sentencia antecedente como proveniente de dolo, fraude, colusión o la afectación cierta del derecho al debido proceso legal en que, a criterio razonable del demandante del proceso nulificante, se hubiere incurrido por parte de los demás actores del proceso judicial, incluyendo al juez o jueces, y en su perjuicio; con la finalidad de que, volviendo las cosas al estado anterior al juzgamiento antecedente, en el proceso nulificante se deje éste sin efecto y se rejuzgue el derecho del demandante del proceso nulificante y que considera perdido, no recono-

\footnotetext{
En sus tres "tamaños" o estándares: Mayor de Conocimiento, Abreviado de Conocimiento o Sumarísimo de Conocimiento.
} 
cido o no acogido con injusticia dolosa, fraudulenta, colusión o la grave afectación del derecho al debido proceso legal ${ }^{13}$, entendido éste como:

"El Debido Proceso Legal (Due Process of Law) constituye la primera de las Garantias Constitucionales de la Administración de Justicia al permitir el acceso libre e irrestricto a los Tribunales de Justicia a todo ciudadano con el objeto de someter su derecho en disputa a la resolución del Organo Jurisdiccional, para que sea dirimida con certeza y eficacia, esto es, para que pueda hacer realidad el Derecho Material en el caso concreto sintetizando la justicia inherente de ese derecho.

[...]

El Due Process of Law no es otra cosa, se señala, que la institución de origen anglosajón referida al debido proceso legal como garantía con sustrato constitucional del proceso judicial, concepto que surge del orden jurisprudencial y que tiende a rodear al proceso de las garantias minimas de equidad y justicia que respaldan la legitimidad de la certeza del derecho finalmente determinado en sus resultados. Por ello, el Debido Proceso Legal-que garantiza la correcta aplicación y vigencia del proceso judicial- es a su vez garantía de una tutela judicial efectiva y ello, a su vez, es elemento indispensable para la consecución de la finalidad del propio proceso judicial."

En el presente caso, el proceso antecedente está conformado por una acción de amparo constitucional que el demandante interpuso y ganó, como garantía judicial en la protección de los derechos constitucionales en tanto afectado-demandante. En consecuencia, la pregunta que consecuentemente puede hacerse en este caso es la siguiente: ¿puede una Acción de Amparo Constitucional constituir válidamente el proceso antecedente de la acción nulificante de que trata el artículo 178 del Código Procesal Civil?

No parece que la respuesta determine que ello sea factible ni válidamente procedente, independientemente de que el pretensor de esta acción nulificante sea el Estado o un particular, ya que para estos efectos da lo mismo.

En efecto, independientemente de la naturaleza del derecho que la pretensión judicial "ordinaria", "civil" o de orden "material" que, en general, pueda contener, es de advertirse que el proceso judicial normalmente responde a una dual finalidad: i) de modo concreto, solucionar

13. Quiroga León, Aníbal, op. cit. pp. 292 y ss. 
un conflicto jurídico de intereses o resolver una incertidumbre jurídica, haciendo efectivos los derechos substanciales de las personas involucradas; y ii) de modo abstracto, otorgar paz social a la comunidad a través de los mecanismos de la administración de justicia (Art. III del Título Preliminar del Código Procesal Civil).

Por el contrario, la finalidad de la acción de amparo constitucional, prevista expresamente en la Constitución (art. 200, inc. 2, de la Constitución), se halla definida en los artículos 1 y 2 de la ley 23506, que a la letra dicen:

"Art. 1.- El objeto de las acciones de garantía es el reponer las cosas al estado anterior a la violación o amenaza de violación de un derecho constitucional."

"Art. 2.- Las acciones de garantía proceden en los casos en que se violen o amenacen los derechos constitucionales por acción, o por omisión, de actos de cumplimiento obligatorio."

Por lo demás, al ser hoy ésta una norma pre-constitucional, debe sẹr interpretada extensivamente a la luz del propio inciso 2 del artículo 200 de la Constitución ${ }^{14}$, que a la letra dice:

"Art. 200.- Son garantias constitucionales:

[...]

2. La Acción de Amparo, que procede contra el hecho u omisión por parte de cualquier autoridad, funcionario o persona, que vulnera o amenaza los demás derechos reconocidos por la Constitución, con excepción de los señalados en el inciso siguiente. [Referido a la acción de hábeas data.]

No procede contra normas legales ni contra resoluciones judiciales emanadas de un procedimiento regular." (El agregado es nuestro.)

La naturaleza jurídico-constitucional de la Acción de Amparo, harto diferente de la de una de carácter "civil» u "ordinario", sólo puede ser debidamente estudiada, analizada y aplicada a la luz del Derecho Procesal Constitucional, categoría jurídico-constitucional a la que, ciertamente, no alcanza el Código Procesal Civil. En esta línea de pensamiento, la naturaleza procesal de la acción de amparo puede ser definida como:

14 Texto según reforma constitucional aprobada por ley 26470 , de 9 de junio de 1995 . 
"Un instrumento o medio juridico de protección de derechos constitucionales distintos de la libertad individual, cuya procedencia circunscrita a casos de violación o amenaza inminente de violación de derechos de esa naturaleza, por acción u omisión de cualquier autoridad, funcionario o persona, tiene por objeto el reponer las cosas al estado anterior a dicha violación o amenaza inminente de violación, evitando de esta forma la consumación de un daño jurídico o irreparable. [...] 5.7. ¿Qué tipo de proceso es el Amparo? Habiéndose concluido que el Amparo es un proceso -por cierto, constitucional-, nos corresponde [...] analizar su tipología al interior de la Teoría General del Proceso, de tal forma de poder establecer si es uno de cognición [conocimiento], de condena, de ejecución o cautelar. [...] 5.7.4. Amparo - Proceso Cautelar. Habiendo sido descartados el "proceso de cognición", el "proceso de condena" y el "proceso de ejecución" como categorias subsumidoras del contenido conceptual del Amparo, [...] corresponde en esta etapa analizar si la naturaleza procesal de la referida institución radica en constituir un Proceso Cautelar, tal y como ha sido individualizado y depurado en su calidad de categoría procesal para [estos] efectos [...]. A. La finalidad inmediata del Amparo es la cautela, defensa o preservación de los derechos constitucionales distintos de la libertad individual [...]; B. Si la plena vigencia de los Derechos Humanos, entrevista como una de las metas más importantes de las Constituciones Políticas, representa la situación normal del desenvolvimiento de las relaciones juridicas entre el Estado y las personas, $y$ de éstas entre sí, entonces la situación contraria o anormal estará referida a una en la que el Estado o las personas, en el desenvolvimiento de sus relaciones juridicas con otras personas, invaden sus esferas de derechos constitucionales [...]; C. Desde este punto de vista, los supuestos de violación o amenaza inminente de violación de derechos constitucionales, ante los cuales procede el Amparo, constituyen situaciones particulares de carácter anormal a la plena vigencia de los Derechos Humanos instituidas por la Constitución; D. Ahora bien, si por daño irreparable entendemos la sustracción o disminución de un bien o la abolición o la restricción de un derecho, imposibles de ser revertidas a una situación anterior a su producción, debemos concluir que el Amparo también tiene por finalidad evitar la producción de un daño irreparable [...], se entiende que no tiene objeto -resultando improcedente ${ }^{15}$ - cuando hay de por medio un daño irreparable, pues

15. A este efecto, el artículo 6, inciso 1, de la ley 23506 , en su versión modificada por la ley 25011 , señala textualmente que es improcedente la acción de garantía cuando ha cesado la 
no puede volver las cosas al estado anterior y [...] cuando si puede hacerlo, lo que hace en realidad [...] es evitar la producción de un daño irreparable. [...] habiendo constatado que el amparo se ajusta a la nota esencial y fundamental de los procesos cautelares, es necesario saber si tan noble institución se presenta en realidad como un proceso verdaderamente autónomo [...].»" (Lo agregado es nuestro.)

En consecuencia, aparece evidente que la naturaleza jurídica de la acción de amparo constitucional dista mucho de la naturaleza jurídica de las pretensiones "ordinarias" sobre las que versa el Código Procesal Civil. En un proceso "ordinario" o "civil» de orden legal-material no cabe ni el concepto de daño irreparable, como causal de impedimento de la actuación jurisdiccional (principio non liquet, art. VIII del Título Preliminar del Código Civil, e inc. 8 del art. 139 de la Constitución Política del Estado), ni el concepto de sustracción de la materia, etc. En consecuencia, no aparece incluida ni susceptible de serlo válidamente por la vía de la interpretación extensiva del artículo 178 del Código Procesal Civil, la posibilidad del control de una acción de garantía constitucional (cualquiera ésta sea, a saber, amparo, hábeas corpus, hábeas data o acción de cumplimiento) por medio de la acción judicial de nulidad de cosa juzgada fraudulenta, aun cuando se alegue, con razón o sin ella, que en este proceso antecedente pudiere existir dolo, fraude o colusión. Siendo la acción de garantía constitucional protectiva de los derechos fundamentales, y siendo el debido proceso una de las garantías constitucionales de la administración de justicia, protegidas precisamente por las acciones de garantía constitucionales (p. e., el amparo), resulta difícil conceptualizar que el amparo constitucional pueda ser instrumento procesal violador del debido proceso legal. Por lo demás, la doctrina del Derecho procesal constitucional determina unánimemente que el juzgador del amparo constitucional es un «juez constitucional», cuya premisa mayor del juzgamiento en el proceso de "subsunción normativa" es su interpretación vinculante de la Constitución. Resulta incompatible con tal doctrina, e incongruente con sus postulados, que dicho "juez constitucional" pueda luego ser objeto de "revisión" por otro magistrado, en otro proceso no constitucional, en la búsqueda de una pre-

\footnotetext{
violación o amenaza de violación de un derecho constitucional, o cuando la violación ha devenido irreparable.

1" Heredia Mendoza, Madeleine, Naturaleza procesal de la acción de amparo, Cult. Cuzco S.A., Biblioteca Universitaria de Derecho Constitucional, Aníbal Quiroga León-Director, Lima, 1995, pp. 39 y ss.
} 
tensión legal-material de la que el proceso antecedente carece por sí mismo sin el auxilio de una prestación constitucional.

\section{Conclusiones}

i) Por todo lo expuesto, resulta evidente que no resulta procedente que una acción de amparo constitucional constituya el antecedente judicial de una acción nulificante de nulidad de cosa juzgada fraudulenta de que trata el artículo 178 del Código Procesal Civil.

ii) Una Acción de Amparo Constitucional, con calidad de cosa juzgada constitucional favorable al demandante, no puede ser controlada por ninguna acción judicial ulterior de ninguna índole, naturaleza o denominación, indistintamente de quién sea (Estado o particular) el que pretenda ser accionante válido de esta ulterior acción judicial.

iii) No parece procedente ni adecuado plantear una acción de amparo constitucional contra la resolución ministerial autoritativa del inicio de la acción de nulidad de cosa juzgada fraudulenta, por cuanto ésta -si bien improcedente y carente de fundamento legal- no constituye por sí misma acto violatorio, o amenaza de violación cierta, de derecho constitucional del justiciable. Para la procedencia válida de una acción de amparo constitucional, son tres las premisas subsidiarias-prelativas que deben absolverse, a saber: i) Cuál es el derecho constitucional afectado; ii) Cuál es el hecho violatorio, y iii) Cuál es la relación de causalidad temporal entre el derecho afectado y el hecho afectante, donde la absolución negativa de cualquiera de estas imprescindibles interrogantes da como resultado la no viabilidad jurídica de tal acción de garantía constitucional. Si bien es cierto la autoridad de cosa juzgada es una garantía constitucional de la administración de justicia (Arr. 139, inc. 13 abinitio), y su vulneración puede dar lugar a una acción de garantía constitucional, esta vulneración no es razonable entenderla en el inicio de una posible acción judicial (hecho violador) destinada a enervar (con razón o sin ella) precisamente el carácter imperativo de tal cosa juzgada, tanto más si el ordenamiento jurídico interno prevé un mecanismo apropiado e idóneo para la defensa de tal autoridad de cosa juzgada cuando en juicio posterior se la pretenda desconocer (excepción de cosa juzga$\mathrm{da})$.

iv) Por ello, si se inicia un proceso por sobre la autoridad de cosa juzgada, aun cuando sea el proceso destinado a cuestionar tal auroridad, 
el mecanismo procesal procedente para defender el derecho del titular de la cosa juzgada está consagrado en el inciso 8 del artículo 446 del Código Procesal Civil, como "excepción de cosa juzgada». El inicio de una acción judicial, por más inadmisible o improcedente que fuere, constituye el ejercicio regular de un derecho y la puesta en lícito debate judicial de una pretensión jurídica que el demandante arguye como incierta. En consecuencia, ello en sí mismo no importa violación constitucional defendible a través de una acción de garantía, al margen de que la autoridad de cosa juzgada sea defendible por el medio procesal ya reseñado y que la demanda en sí misma resulta manifiestamente improcedente y carente de una relación jurídico-procesal válida, susceptible de la aplicación de los artículos 465, incisos 1 y 2, y 467 del Código Procesal Civil.

v) No encontramos posibilidad jurídica de detener el inicio de tal proceso judicial, sin perjuicio de que el juez de la causa nulificante inadmita en el acto de su calificación tal demanda por carecer de pretensión jurídica válida. De no hacerlo, además de la excepción de cosa juzgada ya expresada, el tema puede volverse a plantear en la contestación a la demanda y en el acto del saneamiento procesal.

vi) De iniciarse la causa nulificante, inevitablemente sería su objeto rejuzgar lo mismo que fue materia de la acción de amparo antecedente. De encontrar el juez nulificante procedente dicha causa, estaría obligado a volver sobre el fondo de lo que fue juzgado en el amparo constitucional, sólo si determina de modo previo y necesario que en dicha causa antecedente ha habido dolo, fraude, colusión o violación cierta del derecho al debido proceso legal del demandante de la causa nulificante. En ello debe considerarse cumplida la triple identidad que exige la procedencia de la excepción de cosa juzgada.

vii) Si el juez nulificante admitiese tal demanda, sin amparar la excepción ni desestimarla en el auto de saneamiento, resolviendo luego en la sentencia su improcedencia, el demandante puede interponer recurso de apelación ante la Corte Superior de Justicia respectiva, en uso del derecho constitucional a la instancia plural. De ser la Corte Superior, Sala Civil, del mismo parecer, el demandante perdedor tendría la posibilidad de plantear recurso de casación civil, alegando quebrantamiento esencial de forma (error in procedendo) o error en el juzgamiento (error in iudicando), de conformidad con lo dispuesto en el artículo 386 del Código Procesal Civil. En su oportunidad, en este caso la Sala Civil de la Corte Suprema de Justicia de la República podrá -si comparte el criterio del recurso de casación- disponer su admisión y resolución con los efec- 
tos que señala el artículo 396 del Código Procesal ya acotado. La participación de la Corte Suprema, en este caso, es discrecional y facultativa.

viii) Debe procurarse una reforma del artículo 178 del Código Procesal Civil que delimite los alcances materiales de su contenido (p. e., sólo a los procesos "de conocimiento" y a los "abreviados"), dejando fuera de su control los denominados, con mucho candor y poco estilo, "sumarísimos", lo que excluiría del control del proceso nulificante a cualesquier otro proceso judicial tramitado bajo otras normas legales y que respondan a otra racionalidad normativa. Debe limitarse el sujeto activo del proceso a las partes, dejando fuera del mismo a las partes - por obvias razones, pues terminaremos haciendo de la mitad de los magistrados del Poder Judicial litigantes de cuanta causa se interponga en proceso nulificante en contra suya-, y estableciendo con mayor precisión los efectos del fallo nulificante (volver las cosas al estado anterior en el juzgamiento de la pretensión principal), pero en el segundo proceso, sin revivir el primero, por la caótica situación que ello actualmente supone.

San Miguel, Julio de 1996 